\title{
Timed up and go test combined with self-rated multifactorial questionnaire on falls risk and sociodemographic factors predicts falls among community-dwelling older adults better than the timed up and go test on its own
}

This article was published in the following Dove Press journal:

Journal of Multidisciplinary Healthcare

26 October 2017

Number of times this article has been viewed

\author{
Azianah Ibrahim ${ }^{1,2}$ \\ Devinder Kaur Ajit Singh' \\ Suzana Shahar ${ }^{3}$ \\ Mohd Azahadi Omar ${ }^{4}$ \\ 'Physiotherapy Programme, School \\ of Rehabilitation Sciences, Faculty \\ of Health Sciences, Universiti \\ Kebangsaan Malaysia, ${ }^{2}$ Pantai \\ Integrated Rehab Services Sendirian \\ Berhad, Pandan Indah, ${ }^{3}$ Community \\ Rehabilitation and Ageing Research \\ Centre, Faculty of Health Sciences, \\ Universiti Kebangsaan Malaysia, \\ ${ }^{4}$ Institute for Public Health, Ministry \\ of Health, Kuala Lumpur, Malaysia
}

Correspondence: Devinder Kaur Ajit Singh

Physiotherapy Programme, School of Rehabilitation Sciences, Faculty of Health Sciences, Universiti Kebangsaan Malaysia, Jalan Raja Muda Abdul Aziz, 50300 Kuala Lumpur, Malaysia

Tel +60 326878025

Fax +60326878199

Email devinder@ukm.edu.my
Background: Early detection of falls risk among older adults using simple tools may assist in fall prevention strategies. The aim of this study was to identify the best parameters associated with previous falls, either the timed up and go (TUG) test combined with sociodemographic factors and a self-rated multifactorial questionnaire (SRMQ) on falls risk or the TUG on its own. Falls risk was determined based on parameters associated with previous falls.

Design: This was a retrospective cohort study.

Setting: The study was conducted in a community setting.

Participants: The participants were 1,086 community-dwelling older adults, with mean age of 69.6 \pm 5.6 years. Participants were categorized into fallers and nonfallers based on their history of falls in the past 12 months.

Method: Participants' sociodemographic data was taken, and SRMQ consisting of five fallsrelated questions was administered. Participants performed the TUG test twice, and the mean was taken as the result.

Results: A total of 161 participants were categorized as fallers (14.8\%). Multivariate logistic regression analysis showed that the model $\left(\chi^{2}(6)=61.0, p<0.001\right.$, Nagelkerke $\left.R^{2}=0.10\right)$ consisting of the TUG test, sociodemographic factors (gender, cataract/glaucoma and joint pain), as well as the SRMQ items "previous falls history" (Q1) and "worried of falls" (Q5), was more robust in terms of falls risk association compared to that with TUG on its own $\left(\chi^{2}(1)=10.3, p<0.001\right.$, Nagelkerke $R^{2}=0.02$ ).

Conclusion: Combination of sociodemographic factors and SRMQ with TUG is more favorable as an initial falls risk screening tool among community-dwelling older adults. Subsequently, further comprehensive falls risk assessment may be performed in clinical settings to identify the specific impairments for effective management.

Keywords: falls, screening, multifactorial, community, older adults

\section{Introduction}

The number of older adults globally is estimated to double from $12 \%$ to $22 \%$ in year $2050 .{ }^{1}$ Of the 26 million comprising the Malaysian population, $7 \%$ are older adults, and this number is expected to rise up to $15 \%$ in $2035 .^{2}$ Malaysia is projected to achieve an aging nation status by the year 2020 as the median age will increase to 30.3 years. $^{3}$ 
Multidimensional changes in physiological aspects, which include both physical and psychological changes, occur with aging. Generally, reduction in muscle mass and strength, combined with declined balance and gait changes, in older adults, leads to detrimental consequences, which includes falls. This is a prominent burden of disease among older adults based on disability-adjusted life year (DALY) in $2013 .^{4-7}$

Falls are identified as one of the leading causes of injuries among older adults, with prevalence of $30 \%-50 \%$ among older adults aged $\geq 65$ years. ${ }^{89}$ The same trend is seen in our local setting, whereby falls contribute to $47 \%$ older adults attending a primary clinic. ${ }^{10}$ Falls have devastating consequences, ranging from injuries of joints and muscles (38\%), fractures $(28 \%)$ and contusion (27\%) to traumatic brain injuries (1\%). ${ }^{11}$

As a result, older adults develop fear of falls, and this leads to physical inactivity and higher risk of frailty-increased dependency. ${ }^{12-15}$ Older adults are reported to die from falls every 20 minutes probably due to traumatic brain injuries. ${ }^{16}$ In addition, fall-related injuries are categorized as the 20 most expensive medical conditions to treat. ${ }^{17}$ Therefore, prevention of falls is of utmost importance. Evidence-based practice guidelines have recommended early screening for falls and detection. ${ }^{9}{ }^{18}$ However, easy-to-administer and cost-effective fall-screening tools are deemed necessary for self- or largescale screening.

Various easy approaches are available for identifying fallers among older adults, namely, subjective assessments using sociodemographic risk factors and questionnaires such as the self-rated falls risk questionnaire (FRQ), as well as physical assessment tools that include the timed up and go (TUG) and gait speed tests. ${ }^{19-21}$ Sociodemographic factors, such as gender, previous falls history, medical history and eye problems, have been reported as independent fall risk factors in a systematic review. ${ }^{22}$ On the other hand, self-rated FRQ has been formally developed for self-screening, based on robust prospective qualitative study design with an iterative stepwise approach among community-dwelling older adults. ${ }^{23}$ In addition, it has been validated against clinical examinations. ${ }^{20}$

Moreover, subjective and objective assessments such as gait speed (which consists of straight walk) are easy and convenient to perform. In comparison, the TUG test is noted to be a better tool to determine falls as its test components include the movements sit to stand, walking and turning and are related to falls. ${ }^{24}$ The association between the TUG test and falls are conflicting. In a review, it was corroborated that an association between TUG and retrospective falls (past his- tory of falls) is well established. ${ }^{25}$ However, its association with prospective falls is unclear. ${ }^{25}$ It is known that limited number of studies, especially prospective studies $(n=4)$, were reviewed and half of the reviewed studies were conducted among in-patients. The period of follow-up was too wide and ranged from 9 days to 5 years, with varied TUG cutoff values. It is believed that the TUG test is useful to rule in, but not rule out, falls. ${ }^{26}$ However, this notion is arguable in terms of applicability, due to the fact that the TUG test cutoff point is limited to 13.5 seconds. Nevertheless, prospective studies are limited, probably due to costing and logistic issues, and a recent meta-analysis has reported the TUG test as one of the functional measures useful for the identification of future falls risks, based on studies with prospective and retrospective designs. ${ }^{27}$

Besides being cost-effective, simple to perform, not requiring training and relatively quick to administer, TUG is sensitive and specific in identifying fallers. ${ }^{28-30}$ Falls recall in a past year is also reported to have good sensitivity (80\%-89\%) and specificity (90\%-95\%). ${ }^{31}$ One of the challenges in dealing with falls issues is the multifactorial nature of causes. Moreover, self-administered and multifactorial falls risk assessments have been recommended in a number of evidence-based falls practice guidelines. ${ }^{9,18,32-35}$ Most of the falls assessments are either subjective or objective; therefore, it is worth examining if a TUG test combined with identified sociodemographic factors and a self-rated multifactorial questionnaire (SRMQ) associated with falls could more accurately identify fallers among communitydwelling older adults.

The purpose of this study was to identify whether the TUG test on its own or the TUG test combined with sociodemographic factors and an SRMQ is more robust in identifying falls risk among community-dwelling older adults.

\section{Methods}

\section{Participants}

A total of 2,324 community-dwelling older adults from four states that represented central, south, north and east of Malaysia were recruited based on multistage random sampling at Wave 1. This study is part of a large-scale population-based longitudinal study "Towards Useful Ageing (TUA)" (Long-term Research Grant Scheme [LRGS] TUA), which involved three waves with a gap of 18 months. Further details of methodology are as described in an earlier report. ${ }^{36}$ This study was approved by the Medical Research and Ethics Committee of Universiti Kebangsaan Malaysia (UKM 1.5.3.5/244/NN-060-2013). Participants were further 
screened for inclusion criteria and included older adults aged 60 years and above, ambulating independently with or without walking aids. Written and verbal information was provided to all participants. Written informed consent forms were obtained from participants prior to data collection.

Our present study was conducted in Wave 2 of the LRGS TUA study (November 2014-August 2015), and history of falls was taken from the LRGS TUA Wave 1 study (February 2012-February 2013) (Figure 1). Older adults who were unable to comprehend Malay, English, Mandarin or Tamil languages, as well as those diagnosed with severe hearing or vision problems and mild cognitive impairment were excluded. Mild cognitive impairment was categorized based on studies by Petersen et al, ${ }^{37}$ as detailed in the study by Shahar et al..$^{36}$ At Wave 2, 1,086 (553 women and 533 men; mean age: $69.6 \pm 5.6$ years) participants met the inclusion criteria. Participants attended the assessment sessions at community halls in the districts.

\section{Data collection}

In Wave 2, sociodemographic and SRMQ data on falls risk were obtained from participants via interviews, followed by TUG test administration. Details of the assessments are as follows.

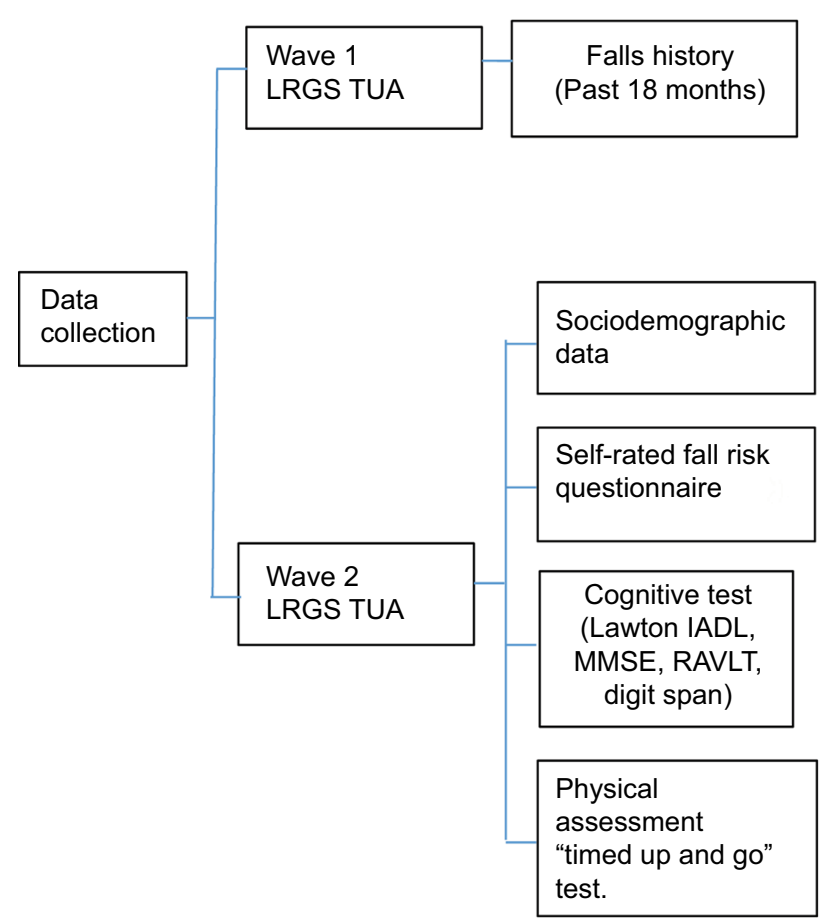

Figure I Framework of methodology in each wave of LRGS TUA.

Abbreviations: IADL, Instrumental Activities of Daily Living; LRGS TUA, Longterm Research Grant Scheme "Towards Useful Ageing"; MMSE, Mini Mental State Examination; RAVLT, Rey Auditory Verbal Learning Test.

\section{Demographic data}

A structured interview was administered to obtain the sociodemographic and clinical data, which include age, gender, race, years of education, self-reported medical conditions (eg, hypertension, joint pain, incontinence and diabetes) and medications.

\section{Questionnaire}

An adapted, self-rated FRQ was used. FRQ has a strong agreement with clinical evaluation (kappa $=0.88, p<0.0001$ ). ${ }^{21}$ The English version was back-translated to Malay language. It was then tested for intrarater reliability, whereby five out of 12 items were found to have strong levels of agreement (kappa $\geq 0.70, p<0.001$ ) and seven items had low levels of agreement. Therefore, only five questions with strong agreement levels were included in this study. Overall scores of these five items had strong levels of agreement (kappa $=0.88$, $p<0.001$ ), tested using intraclass correlation coefficient (ICC). These questions evaluate the presence of risk of falls, which includes history of previous falls in the past 18 months, their gait/balance status, fear of falls, muscle weakness and medications. Participants were interviewed and asked to answer "Yes" or "No" for these questions. History of falls for the past 18 months obtained from Wave 1 was used for Question 1 on "past history of falls".

\section{Falls information}

Information on fall incidents within the past 12 months from the present Wave 2 of the study was used to categorize participants into fallers and nonfallers, while fall incidents within the past 18 months from Wave 1 LRGS TUA data were utilized as history of falls. These data were obtained from Wave 1 of the TUA study repository of the same participants and was based on the following question: "Have you had a fall in the past 18 months?" Falls risk was determined based on parameters associated with previous falls, as it is a reliable indicator of future falls. ${ }^{38} \mathrm{~A}$ fall was defined to participants as "an event whereby a person inadvertently comes to rest on ground or a lower level, excluding intentional change in position to rest on another object" (World Health Organization [WHO $]^{35}$ ).

\section{The TUG test}

In the TUG test, the time taken by participants while rising from an armless chair ( $46 \mathrm{~cm}$ height), for walking $3 \mathrm{~m}$, turning, walking back and sitting down was taken. The TUG test was performed twice consecutively, and the average of the two scores was used for further analyses. Participants were instructed to walk at a normal pace with or without their 
walking aids. The assessor demonstrated the TUG test once to the participants prior to the test. During the test, the assessor walked beside the participant (without touching or supporting) to prevent falls. TUG has very high interrater reliability in community-dwelling older adults (intraclass coefficient of 0.98). ${ }^{30}$ This test was conducted by a physiotherapist.

\section{Statistical analysis}

Sociodemographic data, score of each item in the multifactorial FRQ and the TUG test score were compared between the faller and nonfaller groups, using the independent $t$-test or chi-square test. Variables that were found to be significant in the univariate test were further analyzed using stepwise multivariate regression analysis. Scores for the remaining variables in stepwise multiple logistic regressions were calculated to an integer score based on the odds ratios (ORs) from logistic regression. Finally, receiver operating characteristic curve (ROC) analysis was conducted to identify the best cutoff score for the TUG test among the participants in our study, with maximum sensitivity and specificity, using the Youden Index. Similarly, the best cutoff for the total points score was deter- mined using the Youden Index. Area under the curve (AUC) from ROC analysis was compared to identify the model that had better association with falls risk. Difference of $\geq 0.025$ in the AUC is clinically relevant. ${ }^{39}$ All statistical analyses were performed using Statistical Package for the Social Sciences (SPSS), version 23 (IBM Corp, Armonk, NY, USA).

\section{Results}

Table 1 depicts the characteristics of the participants. A total of $161(14.8 \%)$ out of 1,086 participants were categorized as fallers based on past history of falls at 12 months. Most of the fallers (63.4\%) comprised women. Age, body mass index and most of the self-reported medical histories, sum of diseases and number of medications appeared to have no difference between the faller and nonfaller groups. Only gender, joint pain and cataract/glaucoma were found to be significantly different between the groups $(p<0.05)$. The TUG test was categorized using cutoff point of 11.18 seconds (AUC: 0.6 , sensitivity: 0.5 and specificity: 0.6 ), as obtained using ROC analysis, and it was shown to be significantly different between faller and nonfaller groups.

Table I Characteristics of participants and differences between fallers and nonfallers

\begin{tabular}{|c|c|c|c|c|c|c|c|}
\hline \multirow{2}{*}{$\begin{array}{l}\text { Potential predictor } \\
\text { variables }\end{array}$} & \multicolumn{2}{|l|}{$\begin{array}{l}\text { Fallers } \\
(n=161,14.8 \%)\end{array}$} & \multicolumn{2}{|l|}{$\begin{array}{l}\text { Nonfallers } \\
(n=925,58.2 \%)\end{array}$} & \multirow[t]{2}{*}{$p$-value } & \multirow{2}{*}{\multicolumn{2}{|c|}{$\begin{array}{l}\text { Total } \\
(\mathrm{N}=\mathrm{I}, 086) \\
\text { Mean }( \pm \mathrm{SD})\end{array}$}} \\
\hline & \multicolumn{2}{|l|}{ Mean (士SD) } & \multicolumn{2}{|l|}{ Mean ( $( \pm S D)$} & & & \\
\hline Age, years & \multicolumn{2}{|l|}{$69.9( \pm 6.0)$} & \multicolumn{2}{|l|}{$69.5( \pm 5.5)$} & 0.45 & \multicolumn{2}{|l|}{$69.6( \pm 5.6)$} \\
\hline Body Mass Index, $\mathrm{kg} / \mathrm{m}^{2}$ & \multicolumn{2}{|l|}{$25.2( \pm 4.7)$} & \multicolumn{2}{|l|}{$25.1( \pm 4.5)$} & 0.80 & \multicolumn{2}{|l|}{$25.1( \pm 4.5)$} \\
\hline Sum of disease & \multicolumn{2}{|l|}{$2( \pm I)$} & \multicolumn{2}{|l|}{$2( \pm I)$} & $0.05^{b}$ & \multicolumn{2}{|l|}{$2( \pm I)$} \\
\hline Years of education & \multicolumn{2}{|l|}{$5.4( \pm 3.8)$} & \multicolumn{2}{|l|}{$5.6( \pm 4.0)$} & 0.5 & \multicolumn{2}{|l|}{$5.5( \pm 4.0)$} \\
\hline \multirow[t]{2}{*}{ TUG, seconds } & \multicolumn{2}{|l|}{$12.1( \pm 2.8)$} & \multicolumn{2}{|l|}{$11.3( \pm 2.4)$} & $0.002^{\mathrm{b}}$ & \multicolumn{2}{|l|}{ I I.4 ( \pm 2.5$)$} \\
\hline & $\mathbf{n}$ & $\%$ & $\mathbf{n}$ & $\%$ & $p$-value & $\mathbf{n}$ & $\%$ \\
\hline \multicolumn{8}{|l|}{ Gender } \\
\hline Men & 59 & 36.6 & 474 & 51.2 & $0.01^{\mathrm{a}}$ & 533 & 49.1 \\
\hline Women & 102 & 63.4 & 451 & 48.8 & & 553 & 50.9 \\
\hline High Cholesterol & 74 & 46.0 & 358 & 38.7 & $0.08^{\mathrm{a}}$ & 432 & 39.8 \\
\hline Hypertension & 78 & 41.4 & 453 & 49.0 & $0.90^{\mathrm{a}}$ & 531 & 48.9 \\
\hline Diabetes & 41 & 25.5 & 237 & 25.6 & $0.97^{\mathrm{a}}$ & 278 & 25.6 \\
\hline Heart Disease & 12 & 7.5 & 77 & 8.3 & $0.7 I^{\mathrm{a}}$ & 89 & 8.2 \\
\hline Asthma & 9 & 5.6 & 59 & 6.4 & $0.70^{\mathrm{a}}$ & 68 & 6.3 \\
\hline Cataract/Glaucoma & 32 & 19.9 & 96 & 10.4 & $0.01^{\mathrm{a}}$ & 128 & 11.8 \\
\hline Gout & 12 & 75 & 43 & 4.6 & $0.13^{\mathrm{a}}$ & 55 & 5.1 \\
\hline Joint Pain & 61 & 37.9 & 211 & 22.8 & $<0.00 I^{a}$ & 272 & 25.0 \\
\hline Incontinence & 14 & 8.7 & 94 & 10.2 & $0.13^{\mathrm{a}}$ & 108 & 9.9 \\
\hline Vision Hearing & 13 & 8.1 & 75 & 8.1 & $0.26^{\mathrm{a}}$ & 88 & 8.1 \\
\hline \multicolumn{8}{|l|}{ Number of medication } \\
\hline$\leq 3$ & 152 & 94.4 & 867 & 93.7 & $0.74^{\mathrm{a}}$ & 1019 & 93.8 \\
\hline$\geq 4$ & 9 & 5.6 & 58 & 6.3 & & 67 & 6.3 \\
\hline \multicolumn{8}{|l|}{ TUG, seconds } \\
\hline$<11.18$ & 63 & 39.1 & 488 & 52.8 & $0.002^{\mathrm{a}}$ & 551 & 50.7 \\
\hline$\geq 11.18$ & 98 & 60.9 & 437 & 47.2 & & 535 & 49.3 \\
\hline
\end{tabular}

Notes: "Fallers" had falls over the past 12 mths; "Nonfallers" had no history of falls for the past 12 months. "Chi Square test; bStudent $t$-test. Abbreviation: TUG, timed up and go test. 
Table 2 Scores of fallers and nonfallers on multifactorial falls risk questionnaire

\begin{tabular}{|c|c|c|c|c|c|c|}
\hline \multirow[t]{2}{*}{ Item } & \multicolumn{2}{|c|}{ Fallers $(n=|6|, \mid 4.8 \%)$} & \multicolumn{2}{|c|}{ Nonfallers $(n=925,58.2 \%)$} & \multirow{2}{*}{$\begin{array}{l}\text { Odds ratio } \\
(95 \% \mathrm{Cl})\end{array}$} & \multirow[t]{2}{*}{$p$-value } \\
\hline & $\mathbf{N}$ & $\%$ & $\mathbf{n}$ & $\%$ & & \\
\hline QI Had a fall (past I8 months) & 46 & 28.6 & 153 & 16.2 & $2.02(1.38-2.96)$ & $<0.00 I^{\mathrm{a}}$ \\
\hline Q3 Felt unsteadiness on walking & 59 & 36.6 & 203 & 21.9 & $2.06(1.44-2.94)$ & $<0.00 I^{\mathrm{a}}$ \\
\hline Q5 Worried of falling & 75 & 46.6 & 251 & 27.1 & $2.34(1.66-3.30)$ & $<0.00 I^{\mathrm{a}}$ \\
\hline Q7 Trouble stepping up curb & 46 & 28.6 & 172 & 18.6 & $1.75(1.20-2.56)$ & $0.004^{\mathrm{a}}$ \\
\hline $\begin{array}{l}\text { Q10 Had lightheadedness and tiredness because } \\
\text { of medication }\end{array}$ & 18 & 11.2 & 73 & 7.9 & $1.47(0.85-2.54)$ & $0.17^{\mathrm{a}}$ \\
\hline
\end{tabular}

Note: ${ }^{a}$ Chi-square test.

Table 3 Predictor coefficients for falls predicting model

\begin{tabular}{|c|c|c|c|c|c|}
\hline Model & Item & B & SE & Odds Ratio (95 \% Cl) & Points \\
\hline \multicolumn{6}{|l|}{ I. TUG } \\
\hline \multirow{5}{*}{$\begin{array}{l}\chi^{2}(d f=I, N=I, 086)=10.25, \\
p<0.00 I, \text { Nagelkerke } R^{2}=0.02\end{array}$} & Constant & -2.05 & 0.13 & 0.19 & \\
\hline & & & & & \\
\hline & TUG & 0.55 & 0.17 & $1.74(1.23-2.45)$ & 2 \\
\hline & ( $\geq 11.18$ seconds) & & & & \\
\hline & AUC & 0.57 & 0.006 & $(0.52-0.62)$ & \\
\hline \multicolumn{6}{|c|}{ 2. TUG + Gender+ Cataract/Glaucoma + JointPain $+Q$ I+Q5: } \\
\hline $\begin{array}{l}\chi^{2}(d f=6, N=1,086),=60.95 \\
p<0.001\end{array}$ & Constant & -2.77 & 0.19 & 0.06 & \\
\hline \multirow[t]{8}{*}{ Nagelkerke $R^{2}=0.10$} & TUG & 0.31 & 0.18 & $1.36(0.95-1.95)$ & $\mathrm{I}$ \\
\hline & ( $\geq 11.18$ seconds) & & & & \\
\hline & Gender(Woman) & 0.41 & 0.18 & $1.50([1.05-2.16)$ & 2 \\
\hline & Cataract/Glaucoma & 0.67 & 0.23 & $1.99([1.26-3.14)$ & 2 \\
\hline & Joint Pain & 0.55 & 0.19 & $1.74(1.20-2.51)$ & 2 \\
\hline & QI & 0.64 & 0.20 & $1.90(1.27-2.82)$ & 2 \\
\hline & Q5 & 0.60 & 0.19 & $1.81(1.26-2.61)$ & 2 \\
\hline & AUC & 0.68 & 0.02 & $(0.63-0.73)$ & \\
\hline
\end{tabular}

Notes: B: regression coefficient. Points are rounded number of odds ratio scores for falls predicting model. QI: Previous falls history; Q5: worried of falling. Abbreviations: SE, standard error; AUC, area under the curve; TUG, timed up and go test.

Multifactorial FRQ data (Table 2) showed that most of the participants categorized as fallers had history of falls (Q1 OR: 2.02, 95\% CI: 1.38-2.96), felt unsteadiness on walking (Q3 OR: $2.06,95 \%$ CI: 1.44-2.94), were worried of falling (Q5 OR: 2.34, 95\% CI: 1.66-3.30) and had trouble on stepping up curbs (Q7 OR: 1.75, 95\% CI: 1.20-2.56), significantly $(p<0.05)$ more than the nonfaller group.

Table 3 presents the results of logistic regression analysis on identifying falls risk factors using TUG alone, as Model 1, and TUG with sociodemographic data and SRMQ on falls risk as Model 2. In total, eight variables that were significant in the univariate test (Tables 1 and 2), comprising the TUG, gender, cataract/glaucoma and joint pain and four items from the SRMQ, namely, Q1, Q3, Q5 and Q7, were entered into stepwise backward logistic regression analysis. The AUC of Model 2, which comprised TUG, gender, cataract, joint pain, Q1 and Q5, was 0.68 and had better association with falls risk compared to that of Model 1 (AUC $=0.57$ ). Improvement of AUC in Model 2 by 0.11 ( $\geq 0.025)$ is considered clinically important. ${ }^{39}$ Thus, Model 2 is deemed more robust for screening falls compared to Model 1.
To facilitate the use of the present model in a community or in clinical practice for falls risk identification, the OR scores were rounded to the nearest integer, as shown in Table 3. The total score ranged from zero, without any risk factor, to 11 , with all the risk factors present. Best cutoff of total falls risk score to designate a faller was $\geq 5$, with $74 \%$ specificity.

\section{Discussion}

In this large population based study including 1,086 participants, we examined if the TUG test on its own or when combined with multifactorial falls questions and certain sociodemographic data can identify fallers better among community-dwelling older adults. Using multivariate logistic regression test, we identified six risk factors that were significantly associated with falls among community-dwelling older adults, which include the TUG test, gender, cataract/ glaucoma, joint pain, Q1 (history of falls) and Q5 (worrying of falls). To the best of authors' knowledge, this is the first study to propose simple combined falls assessment tools consisting of TUG test, sociodemographic data and a multifactorial questionnaire. 
Our study results showed that $15 \%$ of the communitydwelling older adults had experienced a fall. This lies within the range of falls prevalence (13\%-27\%) reported by previous studies $^{10,40}$ that were conducted among community-dwelling older adults in our local settings. However, these figures are much lower compared to falls in other settings, namely, clinics and residential institutions, which range from $33 \%$ to $47 \%$ and show a prevalence of $89 \%{ }^{10,40-43}$ In terms of global data, falls frequency of $28 \%-35 \%$ have been reported in several countries, with about $14 \%-15 \%$ in India and China. ${ }^{35,44,45}$ Difference in falls definition and sociodemographic profiles could have probably yielded the variation in number of falls prevalence across countries. ${ }^{34,46}$

Findings of our present study showed that a higher score of TUG test was associated with higher risk of falls and this is consistent with findings from previous studies. ${ }^{10,47-49} \mathrm{TUG}$ is known to assess gait, mobility, lower extremity function, dynamic balance and agility in older adults. ${ }^{50,51}$ Moreover, activities found to be associated with falls, such as walking forward, standing, stand-to-sit motion, initiation of walking and sit-to-stand motion are TUG test components. ${ }^{24}$

TUG test cutoff point for falls assessment in our study was 11.18 seconds, and this is approximately similar to recent study results among 259 British community-dwelling older adults. ${ }^{49}$ However, this TUG cutoff point is much lower than the 13.5 seconds that was proposed in an earlier study conducted among 30 community-dwelling older adults in Seattle. ${ }^{30}$ The plausible explanation for these differences could be due to the manner in which falls were defined in the study. ${ }^{30}$ In the study by Shumway-Cook and Brauer, ${ }^{30}$ older adults with history of two or more falls were considered as fallers, whereas those with a history of single or more falls were categorized as fallers in our study. Poorer physical performance is possible among older adults with recurrent falling. The sensitivity and specificity of TUG, at $50 \%$ and $60 \%$, respectively, in our study might be low. However, it will be useful to identify older adults with falls risk early for further comprehensive assessment and management through such screenings. ${ }^{52}$

Among the personal profile risk factors, only gender, vision impairment (cataract or glaucoma) and joint pain remained as significant risk factors for falls. Women had higher risk of falls. This finding that women are at higher risks for falls is consistent with previous retrospective and prospective design studies. ${ }^{53,54}$ This could be explained by the hormone-associated changes that result in weakness of bone and muscle, in relation to menopause-related issues in women. ${ }^{55}$ Vision acts as a sensory mechanism in the maintenance of balance. ${ }^{56}$ Similar to our findings, in a retrospective design study by Lamoreux et al, ${ }^{57}$ among 3,280 Malay adults, visual impairment was reported to increase risk of falls by two- to fourfolds.

Association of joint pain and falls is inconsistent, and in a recent meta-analysis by Stubbs et al, ${ }^{58}$ it was found that pain increases risk of falls by $43 \%$ and $71 \%$, respectively, in studies that measured falls retrospectively and prospectively. Association of pain and falls can be explained considering the musculoskeletal system, such as joint pathology or neuromuscular effects following pain, and the nervous system. ${ }^{56}$

One of the strengths of this model is that it included multifactorial falls risk with both modifiable and nonmodifiable biological behavioral falls risk factors. This is in line with the recommendation of national falls prevention guidelines. ${ }^{9,18}$ Moreover, in a recent review, it was concluded that cumulative evidence-based assessments were clinically more beneficial falls risk determinants compared to a single test on its own. ${ }^{27}$ Secondly, the association strength of our falls risk screening model (AUC: 0.68 ) does not differ much compared to a previous study related to falls screening model, which incorporated the physical one leg balance test along with other factors (AUC: 0.70 ) ${ }^{59}$ It is noteworthy that the one leg balance test may be inappropriate for older adults as it has been reported to have the highest recorded rates of refusal and inability to perform. ${ }^{60}$ TUG may be more appropriate as it measures functional balance in relation to nature of falls, which occurs mostly in dynamic motion. ${ }^{25}$ Lastly, extra data in addition to TUG are subjective in nature and can be obtained without difficulty.

The limitation of our study is that older adults with falls were determined based on retrospective falls information. However, falls data generally rely on self-reported information, and the recall period of 12 months for falls history has the least error ${ }^{61}$ Prospective falls incidence data would have been preferable, but, it is costly, laborious and time consuming. Moreover, comparison of falls classification using retrospective and prospective designs is found to have good agreement with Bland and Altman limits of agreement of -4.7 to 5.2 (indicating that the two methods do not differ in more than five falls; agreed for $83 \%, x=0.6481$, indicative of good agreement). ${ }^{31}$ This justifies the use of retrospective falls data in our study. Potential recall bias was minimized through exclusion of older adults with mild cognitive impairment. The strength of this study is that it is a large-scale study on multifactorial falls risk assessments with inclusion of physical performance tests conducted using multistage random-sampling methods.

Association between risk factors and falls in isolation are well known. However, information on the association 
between falls risk with combined risk factors are limited. Our study established a simple falls assessment tool that consists of combined falls risk factors, including physical performance (TUG test), sociodemographic factors and a multifactorial questionnaire. We believe that the model is easy and economical to be used for initial falls screening among older adults in community settings. Future studies are required to validate our falls prediction model with actual falls incidence in a prospective study design.

\section{Conclusion}

Based on our study results, the combined model comprising sociodemographic factors, falls-related SRMQ along with TUG is more favorable as an initial falls risk screening tool among community-dwelling older adults. It is hoped that this model will enable clinicians to identify older adults at risk of falls earlier, leading to further assessment, early prevention and management.

\section{Acknowledgments}

The authors thank all participants and the LRGS team for their support and assistance rendered in the study. We also thank Mr Indarpal Singh Didar Singh, who assisted in the proofreading and English language correction of this manuscript. This study was funded by a grant from the Ministry of Higher Education Malaysia via Universiti Kebangsaan Malaysia (LRGS/BU/2012/UKM-UKM/K/01).

\section{Disclosure}

The authors report no conflicts of interest in this work.

\section{References}

1. World Health Organization [webpage on the Internet]. Facts about Ageing; 2014. Available from: http://www.who.int/ageing/about/facts/ en/. Accessed March 21, 2015.

2. NACSCOM. High-Level Meeting on the Regional Review of the Implementation of the Madrid International Plan of Action on Ageing (MIPAA); Macao, China; 2007.

3. Hamid TA, Aizan T. Population Ageing in Malaysia: A Mosaic of Issues, Challenges and Prospects. 1st ed. Serdang: Universiti Putra Malaysia Press; 2015.

4. Crepaldi G, Maggi S. Sarcopenia and osteoporosis: a hazardous duet. J Endocrinol Invest. 2005;28(10 suppl):66-68.

5. Greene BR, Doheny EP, Walsh C, Cunningham C, Crosby L, Kenny RA. Evaluation of falls risk in community-dwelling older adults using body-worn sensors. Gerontology. 2012;58(5):472-480.

6. Salzman B. Gait and balance disorders in older adults - American Family Physician. Am Fam Physician. 2010;82(1):61-68.

7. Haagsma JA, Graetz N, Bolliger I, et al. The global burden of injury: incidence, mortality, disability-adjusted life years and time trends from the Global Burden of Disease study 2013. Inj Prev. 2016;22(1): $3-18$.
8. Hornbrook MC, Stevens VJ, Wingfield DJ, Hollis JF, Greenlick MR, Ory MG. Preventing falls among community-dwelling older persons: results from a randomized trial. Gerontologist. 1994;34(1):16-23.

9. National Institute for Health and Care Excellence. Falls : Assessment and Prevention of Falls in Older People. Manchester: National Institute for Health and Care Excellence; 2013.

10. Singh DKA, Pillai SGK, Tan ST, Tai CC, Shahar S. Association between physiological falls risk and physical performance tests among community-dwelling older adults. Clin Interv Aging. 2015;10:1319-1326.

11. Verma SK, Willetts JL, Corns HL, Marucci-Wellman HR, Lombardi DA, Courtney TK. Falls and fall-related injuries among communitydwelling adults in the United States. PLoS One. 2016;11(3):1-14.

12. World Health Organization [webpage on the Internet]. Falls. WHO; 2016. Available from: http://www.who.int/mediacentre/factsheets/fs344/ en/. Accessed December 16, 2016.

13. Chu L-W, Chiu AYY, Chi I. Impact of falls on the balance, gait, and activities of daily living functioning in community-dwelling Chinese older adults. J Gerontol A Biol Sci Med Sci. 2006;61(4):399-404.

14. Kuzuya M, Masuda Y, Hirakawa Y, et al. Falls of the elderly are associated with burden of caregivers in the community. Int $J$ Geriatr Psychiatry. 2006;21(8):740-745.

15. Suijker JJ, Buurman BM, van Rijn M, et al. A simple validated questionnaire predicted functional decline in community-dwelling older persons: prospective cohort studies. J Clin Epidemiol. 2014;67(10):1121-1130.

16. National Center for Injury Prevention and Control [webpage on the Internet]. Take a Stand on Falls. CDC; 2015. Available from: http:// www.cdc.gov/features/older-adult-falls/. Accessed August 22, 2016.

17. Carroll NV, Slattum PW, Cox FM. The cost of falls among the community-dwelling elderly. J Manag Care Pharm. 2005;11(4):307-316.

18. Department of Health Western Australia. Falls Prevention Model of Care. Perth: Department of Health Western Australia; 2014.

19. Fabre JM, Ellis R, Kosma M, Wood RH. Literature review falls risk factors and a compendium of falls risk screening instruments. J Geriatr Phys Ther. 2010;33:184-197.

20. Rubenstein LZ, Vivrette R, Harker JO, Stevens JA, Kramer BJ. Validating an evidence-based, self-rated fall risk questionnaire (FRQ) for older adults. $J$ Safety Res. 2011;42(6):493-499.

21. Middleton A, Fritz SL. Assessment of gait, balance, and mobility in older adults: considerations for clinicians. Curr Transl Geriatr Gerontol Rep. 2013;2(4):205-214.

22. Kwan MM-S, Close JCT, Wong AKW, Lord SR. Falls incidence, risk factors, and consequences in Chinese older people: a systematic review. J Am Geriatr Soc. 2011;59(3):536-543.

23. Vivrette RL, Rubenstein LZ, Martin JL, Josephson KR, Kramer BJ. Development of a fall-risk self assessment for community dwelling seniors. J Aging Phys Act. 2011;19(1):16-29.

24. Robinovitch SN, Feldman F, Yang Y, et al. Video capture of the circumstances of falls in elderly people residing in long-term care: an observational study. Lancet. 2013;381(9860):47-54.

25. Beauchet O, Fantino B, Allali G, Muir SW, Montero-Odasso M, Annweiler C. Timed up and go test and risk of falls in older adults: a systematic review. J Nutr Health Aging. 2011;15(10):933-938.

26. Barry E, Galvin R, Keogh C, Horgan F, Fahey T. Is the timed up and go test a useful predictor of risk of falls in community dwelling older adults: a systematic review and meta-analysis. BMC Geriatr. 2014;14:14.

27. Lusardi MM, Fritz S, Middleton A, et al. Determining risk of falls in community dwelling older adults: a systematic review and meta-analysis using posttest probability. $J$ Geriatr Phys Ther. 2017;40:1-36.

28. Ganz DA, Bao Y, Shekelle PG, Rubenstein LZ. Will my patient fall? Am Med Assoc. 2007;297(1):77-86.

29. Podsiadlo D, Richardson S. The timed "Up \& Go": a test of basic functional mobility for frail elderly persons. $J$ Am Geriatr Soc. 1991;39(2):142-148.

30. Shumway-Cook A, Brauer S. Research report predicting the probability for falls in community-dwelling older adults using the timed up \& go test. Phys Ther. 2000;80:896-903. 
31. Kunkel D, Pickering RM, Ashburn AM. Comparison of retrospective interviews and prospective diaries to facilitate fall reports among people with stroke Research letters. Age Ageing. 2010;76:277-280.

32. Moncada LVV. Management of falls in older persons: a prescription for prevention. Am Fam Physician. 2011;84(11):1267-1276.

33. National Center for Injury Prevention and Control. Preventing Falls: How to Develop Community-based Fall Prevention Programs for Older Adults; 2008:1-95. Available from: http://www.cdc.gov/homeandrecreationalsafety/images/cdc_guide-a.pdf. Accessed August 30, 2017.

34. Gillespie LD, Robertson MC, Gillespie WJ. Interventions for preventing falls in older people living in the community. Cochrane Database Syst Rev. 2012;2(9):CD007146.

35. World Health Organization. WHO Global Report on Falls Prevention in Older Age WHO Global Report on Falls Prevention in Older Age. Geneva: WHO; 2007:1-7.

36. Shahar S, Omar A, Vanoh D, et al. Approaches in methodology for population-based longitudinal study on neuroprotective model for healthy longevity (TUA) among Malaysian Older Adults. Aging Clin Exp Res. 2016;28(6):1089-1104.

37. Petersen RC, Caracciolo B, Brayne C, Gauthier S, Jelic V, Fratiglioni L. Mild cognitive impairment: a concept in evolution. J Intern Med. 2014;275(3):214-228.

38. Panel on Prevention of Falls in Older Persons,American Geriatrics Society, British Geriatrics Society. Summary of the updated American Geriatrics Society/British Geriatrics Society clinical practice guideline for prevention of falls in older persons. J Am Geriatr Soc. 2011;59(1):148-157.

39. Apfel CC, Kranke P, Greim CA, Roewer N. What can be expected from risk scores for predicting postoperative nausea and vomiting? $\mathrm{Br}$ J Anaesth. 2001;86(6):822-827.

40. Rizawati M, Mas AS. Home environment and fall at home among the elderly in Masjid Tanah Province. JUMMEC. 2008;11(2):72-82.

41. Hui CS, Shahar S, Soon LF, Ramli A. Sejarah jatuh dan hubungannya dengan status pemakanan di kalangan pesakit warga tua. [History of falls and its relationship with nutritional status among older adults]. Sains Malays. 2012;41(3):379-385. Malay.

42. Sazlina SG, Krishnan R, Shamsul AS, Zaiton A, Visvanathan R. Prevalence of falls among older people attending a primary care clinic in Kuala Lumpur, Malaysia. Malays J Community Heal. 2008;14(1):11-16.

43. Singh DK, Manaf ZA, Yusoff NAM, Muhammad NA, Phan MF, Shahar S. Correlation between nutritional status and comprehensive physical performance measures among older adults with undernourishment in residential institutions. Clin Interv Aging. 2014;9:1415-1423.

44. Wu TY, Chie WC, Yang RS, Kuo KL, Wong WK, Liaw CK. Risk factors for single and recurrent falls: a prospective study of falls in community dwelling seniors without cognitive impairment. Prev Med (Baltim). 2013;57(5):511-517.

45. Krishnaswamy DB, Usha DG. Falls in Older People: National/Regional Review - India; 2006. Available from: http://www.who.int/ageing/ projects/SEARO.pdf. Accessed August 20, 2017.

46. Han BH, Ferris R, Blaum C. Exploring ethnic and racial differences in falls among older adults. J Community Health. 2014;39(6):1241-1247.
47. Arnold CM, Faulkner RA. The history of falls and the association of the timed up and go test to falls and near-falls in older adults with hip osteoarthritis. BMC Geriatr. 2007;7:17.

48. Yamada M, Arai H, Nagai K, Tanaka B, Uehara T, Aoyama T. Development of a new fall risk assessment index for older adults. Int $J$ Gerontol. 2012;6(3):160-162.

49. Kojima G, Kendrick D, Skelton DA, Morris RW, Gawler S, Iliffe S. Does the timed up and go test predict future falls among British community-dwelling older people: a prospective cohort study nested within a randomised controlled trial. BMC Geriatr. 2015;15:155.

50. Garber CE, Greaney ML, Riebe D, Nigg CR, Burbank PA, Clark PG. Physical and mental health-related correlates of physical function in community dwelling older adults: a cross sectional study. BMC Geriatr. 2010;10:6.

51. Uemura K, Shimada H, Makizako H, et al. Cognitive function affects trainability for physical performance in exercise intervention among older adults with mild cognitive impairment. Clin Interv Aging. 2013;8:97-102.

52. Morris R, Harwood RH, Baker R, Sahota O, Armstrong S, Masud T. A comparison of different balance tests in the prediction of falls in older women with vertebral fractures: a cohort study. Age Ageing. 2007;36(1):78-83.

53. Tromp AM, Smit JH, Deeg DJ, Bouter LM, Lips P. Predictors for falls and fractures in the Longitudinal Aging Study Amsterdam. $J$ Bone Miner Res. 1998;13(12):1932-1939.

54. Verma SK, Willetts JL, Corns HL, Marucci-Wellman HR. Falls and fall-related injuries among community-dwelling adults in the United States. PLoS One. 2016;11(3):e0150939.

55. Daly RM, Rosengren BE, Alwis G, Ahlborg HG, Sernbo I, Karlsson MK. Gender specific age-related changes in bone density, muscle strength and functional performance in the elderly : a-10 year prospective population-based study. BMC Geriatr. 2013;13(71):1-9.

56. Harwood RH. Visual problems and falls. Age Ageing. 2001;30(suppl 4):13-18.

57. Lamoreux EL, Chong E, Wang JJ, et al. Visual impairment, causes of vision loss, and falls: The Singapore Malay eye study. Investig Ophthalmol Vis Sci. 2008;49(2):528-533.

58. Stubbs B, Binnekade T, Eggermont L, Sepehry AA, Patchay S, Schofield P. Pain and the risk for falls in community-dwelling older adults: systematic review and meta-analysis. Arch Phys Med Rehabil. 2014;95(1):175. e9-187.e9.

59. Bongue B, Dupré C, Beauchet O, Rossat A, Fantino B, Colvez A. A screening tool with five risk factors was developed for fallrisk prediction in community-dwelling elderly. J Clin Epidemiol. 2011;64(10):1152-1160.

60. Lin M-R, Hwang H-F, Hu M-H, Wu H-DI, Wang Y-W, Huang F-C. Psychometric comparisons of the timed up and go, one-leg stand, functional reach, and tinetti balance measures in community-dwelling older people. J Am Geriatr Soc. 2004;52(8):1343-1348.

61. Cummings SR, Nevitt MC, Kidd S. Forgetting falls. J Am Geriatr Soc. 1988;36(7):613-616.
Journal of Multidisciplinary Healthcare

\section{Publish your work in this journal}

The Journal of Multidisciplinary Healthcare is an international, peerreviewed open-access journal that aims to represent and publish research in healthcare areas delivered by practitioners of different disciplines. This includes studies and reviews conducted by multidisciplinary teams as well as research which evaluates the results or conduct of such teams or health
Dovepress

care processes in general. The journal covers a very wide range of areas and welcomes submissions from practitioners at all levels, from all over the world. The manuscript management system is completely online and includes a very quick and fair peer-review system. Visit http://www.dovepress.com/ testimonials.php to read real quotes from published authors. 